\title{
Emprego formal e exportação: o caso da soja na região sul do Brasil
}

\author{
Ezequiel Henrique Hedlund \\ André Vinicius Marujo² \\ Ana Julya de $\mathrm{Melo}^{3}$
}

Submissão: $22 / 12 / 2020$

Aceite: 09/06/2021

\section{Resumo}

O estudo tem como objetivo analisar a empregabilidade formal do cultivo de soja no Sul do Brasil de 2006 a 2016, a fim de comparar o progresso das exportações da soja do mesmo período aos resultados que serão apresentados. Os fundamentos teóricos são baseados em estudos sobre a teoria da base de exportação, adotando nesta abordagem uma estatística descritiva para análise dos dados coletados. A teoria da Base de Exportação entende que a maneira de alcançar o desenvolvimento de uma região deve começar impulsionando as exportações, fomentando novos setores, multiplicando a renda e criando novos empregos. No entanto, a pesquisa concluiu que essa premissa não foi observada no cultivo de soja na região sul durante o período analisado. Entre 2006 e 2016, a região sul sofreu uma queda de $21 \%$ nos postos de trabalho formais, enquanto as exportações tiveram um aumento exponencial pautado no crescimento da área cultivada e da produtividade cada vez maior. Tal explicação é respaldada em dois pontos principais que abarcam a modernização e informalidade no emprego agrícola.

Palavras-chave: Emprego formal; Exportação; Soja.

\section{Employment formal and export:The soy case in the south Brazil region}

\begin{abstract}
The study aims to analyze the formal employability of soybean cultivation in southern Brazil from 2006 to 2016, in order to compare the progress of soybean exports from the same period to the results that will be presented. The theoretical foundations are based on studies on export base theory, adopting in this approach a descriptive statistics for analysis of the collected data. The Export Base theory understands that the way to achieve the development of a region must start by boosting exports, fostering new sectors, multiplying income and creating new jobs. However, the research concluded that this premise was not observed in soybean cultivation in the southern region during the analyzed period. Between 2006 and 2016, the southern region experienced a 21\% drop in formal jobs, while exports saw an exponential increase based on growing acreage and increasing productivity. This explanation is supported by two main points covering modernization and informality in agricultural employment.
\end{abstract}

Keywords: Formal Employment; Exportation; Soy.

\section{Introdução}

No mercado mundial agrícola, conforme Soares (2019), a soja tem sido o produto mais comercializado e vendido, impactando fortemente na economia de países desenvolvidos e, principalmente, nos em desenvolvimento. Na safra de 2017/2018, o maior produtor do grãos de soja foram os Estados Unidos (EUA) com cerca de 36 milhões de hectares plantados, uma

\footnotetext{
${ }^{1}$ Mestrando do Programa de Pós-Graduação em Políticas Públicas e Desenvolvimento na Universidade Federal da Integração Latino-Americana (UNILA). E-mail: ezequielhh@gmail.com

${ }^{2}$ Mestrado em Políticas Públicas e Desenvolvimento (UNILA). E-mail: andremarujo1@hotmail.com

${ }^{3}$ Mestranda do Programa de Pós-Graduação em Políticas Públicas e Desenvolvimento da Universidade Federal da Integração Latino-Americana (UNILA). E-mail: anajulya95@hotmail.com
} 
produção total de 119,5 milhões de toneladas e produtividade de $3.299 \mathrm{~kg} / \mathrm{ha}$. Em segundo lugar do ranking mundial ficou o Brasil, com um total de 35 milhões de hectares plantados, 116 milhões de toneladas produzidas e uma produtividade de $3.333 \mathrm{~kg} / \mathrm{ha}$, ultrapassando à dos EUA (EMBRAPA, 2018).

No entanto, neste ano esse cenário vem mudando, com o Brasil assumindo a liderança na produção mundial de soja conforme estimativa elaborada pelo Departamento de Agricultura Norte-americano. Estima-se que o Brasil irá colher 123 milhões de toneladas do grão na safra de 2019/2020, superior aos 112,95 milhões de toneladas estimados para o EUA (REUTERS, 2019).

Conforme Teixeira (2005), a produção de soja está diretamente vinculada à produção agrícola que, nas últimas décadas, sofreu grandes mudanças. Após a Segunda Guerra Mundial houve uma impactante transformação batizada de "modernização agrícola". O autor relata ainda que o Brasil começou a sentir os reflexos de tal modernização a partir na década de 1950, principalmente nas regiões Sul e Sudeste. Considerado um movimento extremamente dinâmico, o desenvolvimento tecnológico na agricultura trouxe impactos em diferentes setores da economia, inclusive no mercado de trabalho.

Nesta vertente, tem-se que toda a evolução em relação a recente modernização na produção e exportação de soja no Brasil influenciou direta e negativamente na empregabilidade brasileira, ora por conta da necessidade de produção em massa, ora pela prostituição da mão-de-obra através do trabalho informal. Visto isso, objetiva-se analisar a empregabilidade formal do cultivo de soja na região Sul do Brasil no período de 2006 a 2016, de modo a comparar o progresso da exportação de soja do mesmo período em relação aos resultados que serão apresentados.

\section{Exportação como desenvolvimento}

David Ricardo, em sua teoria das vantagens comparativas, evidência a importância da produção e exportação de produtos que a nação possui vantagem (em relação a outras), tal situação tenderia a maximizar a produção mundial e a gerar divisas para os países importarem os produtos dos quais não conseguissem produzir internamente (ou não possuem vantagens). Segundo Oliveira, Nobrega e Medeiros (2012), este tipo de modelo econômico que prioriza a exportação como fator chave para o desenvolvimento de uma região (ou país) foi presente no crescimento de países do sudeste asiáticos, como é o caso da China e da Coréia do Sul. 
Já no caso brasileiro, em grande parte de sua história o país foi dependente da exportação como fonte de renda econômica, principalmente focada em produtos primários. Destaca-se o ciclo da cana de açúcar no período colonial que, apesar de impulsionar a economia, não foi capaz de multiplicar a renda gerada uma vez que esta esteve muito concentrada. Por outro lado, o ciclo do café do século XX apresentou características mais desenvolvimentistas, dado que a renda obtida pelas exportações foi convertida na construção de ferrovias que tinham como o intuito de escoar a produção nacional para os portos. Cabe destacar também que corroborou em incentivos para as indústrias pós-crise 1929 (OLIVEIRA; NOBREGA; MEDEIROS, 2012).

Desde 2011, o Brasil vem apresentando uma queda nos níveis de exportações, passando de US\$ 261 bilhões para US\$ 191 bilhões em 2016, queda de 37\% entre o período conforme pode ser observado no gráfico 1. A estagnação econômica que o país vem passando nos últimos anos tem corroborado para essa redução nas exportações. Apesar dessa redução, o produto que atualmente vem impulsionando as exportações brasileiras é a soja com $10 \%$ de representação, seguido do minério de ferro $(7,4 \%)$ e o açúcar $(5,7 \%)$. Tal distribuição evidencia a dependência histórica que o país possui na exportação de produtos primários.

\section{Gráfico 1 - Exportações brasileiras entre os anos de 2006 e 2016 em bilhões de dólares}

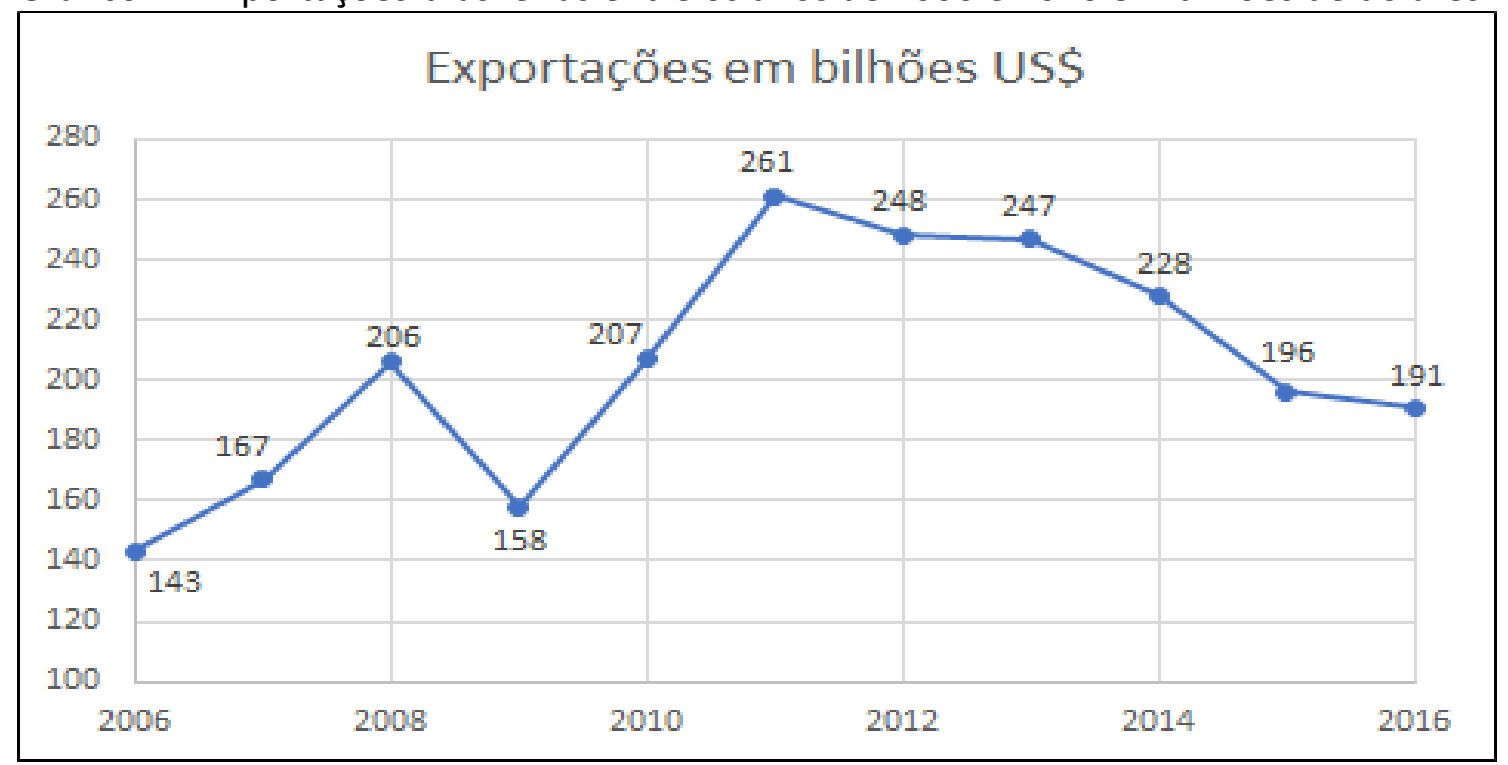

Fonte: Atlas da Complexidade Econômica, 2019.

Apesar da instabilidade nas exportações, esta vem a anos incentivando o crescimento e desenvolvimento da nação, contribuindo para criação e modernização das bases industriais e na geração de emprego, renda e divisas. Tal relação entre exportações e desenvolvimento é evidenciada pela Teoria da Base de Exportação. 
A Teoria da Base da Exportação nada mais é do que uma derivação da Teoria da Base Econômica que propunha a explicação do desenvolvimento de uma região baseado no nível de exportações. No entanto, dado a limitada capacidade de explicação de variações no nível de desenvolvimento de uma região no longo prazo, a Teoria da Base de exportação é construída com base em uma crítica na Teoria da Base Econômica. Assim como a teoria antecessora, a Teoria da Base das Exportações considera que as exportações seriam o principal estímulo que desencadearia o processo de desenvolvimento (OLIVEIRA, 2008).

Considerado como um dos pioneiros a tratar do conceito, Douglass North argumenta tal importância das exportações para o desenvolvimento de uma região: "Clearly the export base plays a vital role in determining the level of absolute and per capita income of a region" (NORTH, 1955, p. 250). Portanto, Oliveira (2008) afirma que a teoria se baseia na existência de dois principais tipos de atividades: i) atividades básicas, principal atividade responsável pela exportação dos produtos para outras regiões (força motriz da economia); ii) atividades nãobásicas, caracterizadas por prestar suporte às atividades exportadoras (básicas).

Lima et al. (2013) destaca que o desenvolvimento de uma determinada região não necessitaria primordialmente da renda local, dado que o desencadeamento inicial para o desenvolvimento de uma região partiria da renda externa (proveniente da compra de produtos locais) que, associados a existência do efeito multiplicador nas economias, incentivaria a criação de outros setores relacionados à atividade principal. Tal efeito multiplicador é o mesmo desenvolvido pela Teoria Keynesiana e pode ser definido como:

$$
\mathfrak{l}=1 / 1-b+m
$$

Sendo "b" a propensão marginal a consumir e " $\mathrm{m}$ " a propensão marginal a importar. Portanto, quanto maior for a propensão marginal a consumir e menor for a propensão marginal a importar, maior tende a ser o efeito multiplicador, isto é, a renda tenderia a se multiplicar em uma escala maior na região. Em síntese, segundo Oliveira (2008), a teoria da base da exportação poderia ser simplificada pela seguinte equação:

$$
Y j=i \quad X j
$$


Sendo, a variável Yj corresponde ao produto da região j; ì ao efeito multiplicador (conforme definido na fórmula 1); e Xj simboliza o nível de exportações da região j para o resto do mundo.

Tal relação evidenciada na fórmula (2) é explicada pelos autores abaixo:

\begin{abstract}
"O aumento da produção das atividades base teria o poder de exercer um efeito multiplicador sobre a economia local influenciando o surgimento das atividades nãobase. As exportações constituem a principal força desencadeadora do processo de desenvolvimento à medida que as atividades base, que vendem seus produtos para os não residentes, incentivam o desenvolvimento das atividades não-base, de mercado local, e complementares às atividades base." (MONTAGNHAN; SHIKIDA, 2012, p. 110).
\end{abstract}

\title{
3 Caracterização do caso
}

Nesta seção buscou-se apresentar um estudo de caso da relação entre as exportações do grão de soja da região Sul do Brasil com a geração de emprego ligado a atividade.

\subsection{Exportações do grão de soja no Brasil}

De acordo com a EMBRAPA (2019), a soja hoje é o principal produto agrícola da pauta de exportações do Brasil, ocupando área superior a 35 milhões de hectares na safra de 2017/2018. O primeiro registro de cultivo no Brasil tem data em 1914 no município de Santa Rosa - RS, mas somente a partir dos anos de 1940 que adquiriu alguma importância econômica, merecendo o primeiro registro estatístico nacional em 1941 conforme Silva et al. (2011).

Nas palavras de Júnior (2014), ainda que o consumo interno tenha crescido, o cultivo de soja no Brasil esteve, desde meados de 1960 , voltado para a exportação, chegando a ter $71 \%$ da produção colhida enviada ao mercado externo em 2012. O grão de soja foi ganhando espaço nas exportações no final da década de 1990, ficando entre os cinco produtos mais exportados da agricultura brasileira, no entanto, somente foi a partir do ano de 2000 que o grão de soja de fato passou a ser líder de exportações no mercado, com 11,91\% de participação.

Desde então, verificou-se um crescimento considerável da participação do grão de soja nas exportações. No período de 2006 a 2016, apesar da instabilidade ao longo da série, teve um aumento de participação no total de exportações de 12,81\% em 2006 para 22,85\% em 2016, chegando ao pico de representar $1 / 4$ das exportações da agricultura brasileira em 2014, conforme pode ser observado no gráfico 2 . 


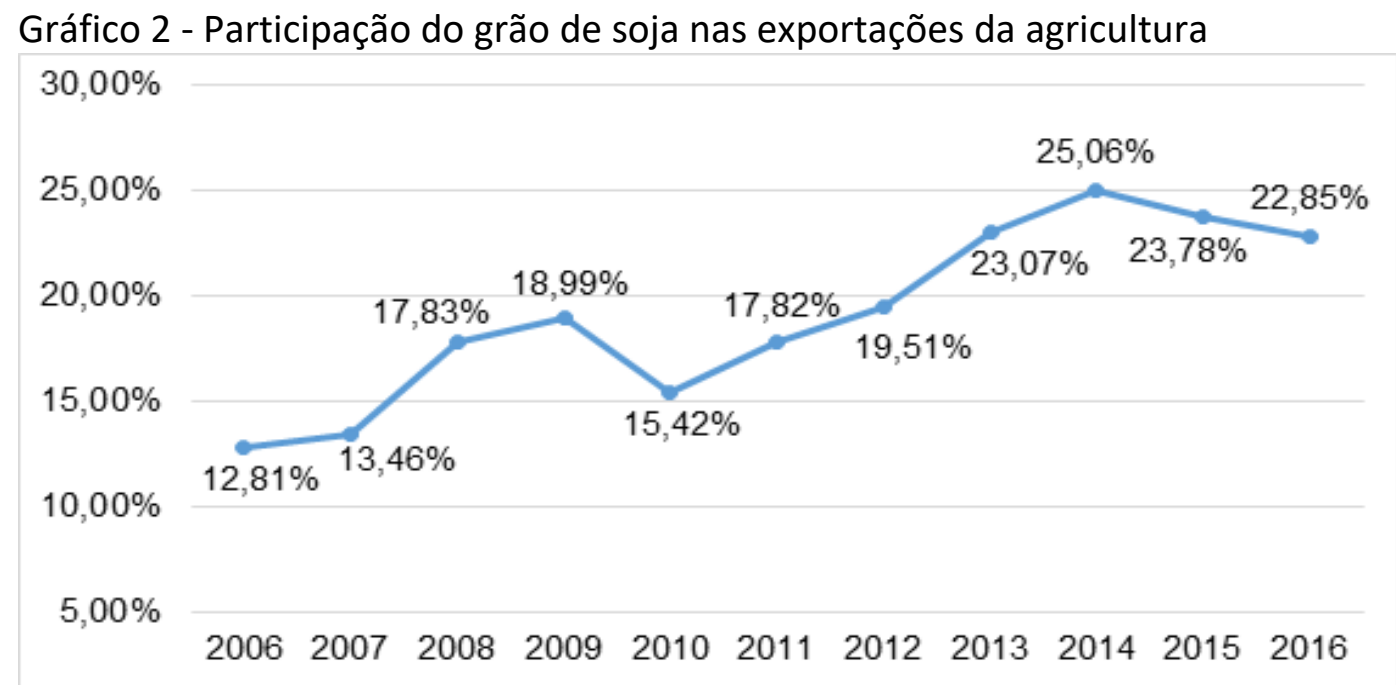

Fonte: Atlas da Complexidade Econômica (2019).

No que se refere ao destino das exportações do grão de soja, dentre os anos de 2006 a 2016 a maior parte das exportações brasileiras tem sido alocadas no mercado asiático, como pode ser visualizado na figura 1.

Figura 1 - Destino das exportações do grão de soja brasileiro entre 2006 e 2016

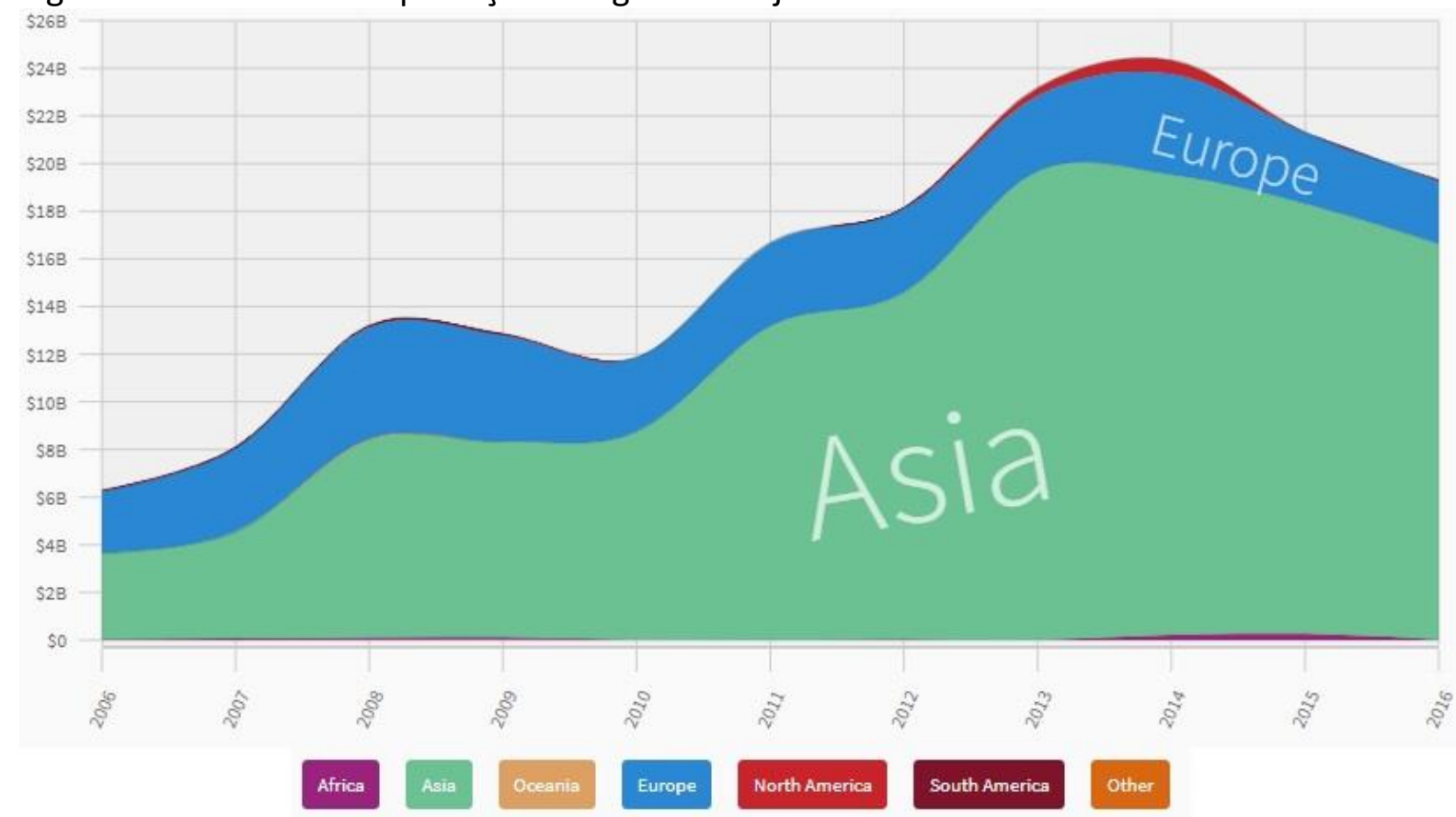

Fonte: Atlas da Complexidade Econômica, 2019.

A China lidera esse ranking de importação do produto desde 2004, apresentado aumento em sua participação ao decorrer dos anos. Em específico, essa representatividade teve um incremento de 45,2\% para 73,63\% entre 2006 e 2016 respectivamente. Segundo a 
Abag (2015), a demanda da China pela soja dobrou entre 2000 e 2009 e, ainda, há a estimativa de um aumento na importação em 59\% até 2021-2022.

3.2 A região sul do Brasil na exportação do grão de soja

A região Sul do Brasil ocupa mais de 7\% do território brasileiro, é uma das principais regiões agrícolas do Brasil, principalmente de grãos e frutíferas de clima temperado (WREGE et al., 2012). Dos 95,5 milhões de toneladas de grãos produzidas no país em 2016, a região sul foi responsável pela produção de 35,3 milhões de tonelada, representando cerca de $37 \%$ da produção nacional. A produção, produtividade e área plantada no período analisado são representadas no quadro 1.

Quadro 1 - Área plantada, produção e produtividade da soja na região Sul entre 2006 e 2016

\begin{tabular}{|l|c|c|c|}
\hline Ano & Área Plantada (mil ha) & Produção (mil t) & Produtividade (kg/ha) \\
\hline $2005 / 06$ & 8.294 & 18.250 & 2.200 \\
\hline $2006 / 07$ & 8.247 & 22.945 & 2.782 \\
\hline $2007 / 08$ & 8.184 & 20.618 & 2.519 \\
\hline $2008 / 09$ & 8.276 & 18.398 & 2.223 \\
\hline $2009 / 10$ & 8.901 & 25.643 & 2.881 \\
\hline $2010 / 11$ & 9.133 & 28.534 & 3.124 \\
\hline $2011 / 12$ & 9.106 & 18.554 & 2.038 \\
\hline $2012 / 13$ & 9.884 & 30.025 & 3.038 \\
\hline $2013 / 14$ & 10.493 & 29.293 & 2.792 \\
\hline $2014 / 15$ & 11.074 & 34.012 & 3.071 \\
\hline $2015 / 16$ & 11.539 & 35.318 & 3.061 \\
\hline
\end{tabular}

Fonte: CONAB (2019).

No período analisado, a região Sul conseguiu manter uma tendência de crescimento. A área plantada teve uma evolução de 8.294 milhões de hectares para 11.539, enquanto a produtividade se elevou de $2.200 \mathrm{~kg} / \mathrm{ha}$ para $3.061 \mathrm{Kg} / \mathrm{ha}$, aumento de $39 \%$ em ambos os casos. Cabe destacar que a produção obteve um aumento de $94 \%$ no período.

Desse total produzido, os estados do Paraná e do Rio Grande do Sul são responsáveis por $94 \%$ da produção da região. Conforme gráfico 3, de modo geral, a produção de ambos os 
estados tangenciam no mesmo sentido e entre 2006 e 2016, apesar do Paraná continuar com uma produção superior ao do Rio Grande do Sul, essa diferença reduziu de 1.870 milhões de toneladas para 781 milhões de toneladas, demonstrando uma evolução maior do Estado do Rio Grande do Sul no período.

Gráfico 3 - Produção (mil t) de soja no Paraná e no Rio Grande do Sul

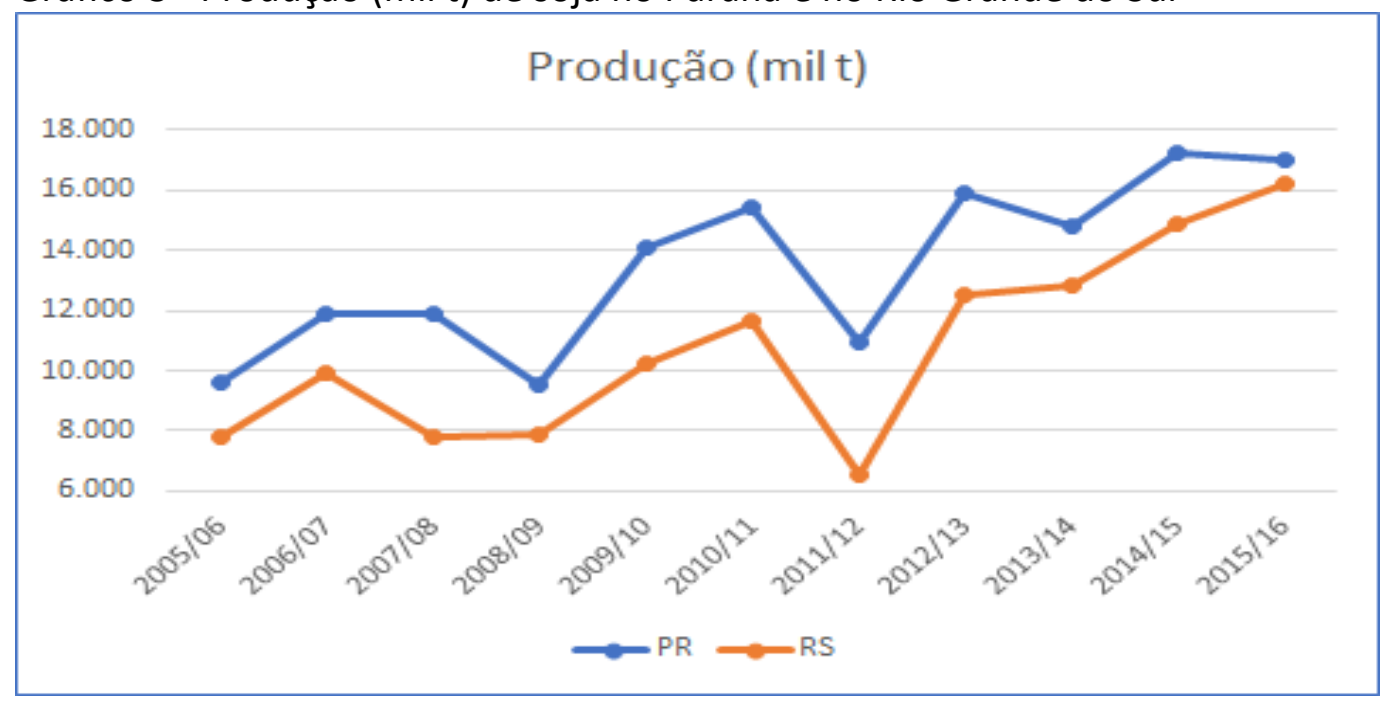

Fonte: CONAB (2019).

Apesar da área plantada entre os dois estados foram similares no período, 3.982 milhões de hectares no Paraná e 3.967 milhões de hectares no Rio Grande do Sul em 2006; e 5.445 mil ha e 5.455 mil ha respectivamente em 2016. Nota-se que o estado do Rio Grande do Sul apresentou uma melhora considerável em sua produtividade, tal situação, é evidenciada no gráfico 4. Enquanto o Paraná obteve um aumento de $29 \%$ em sua produtividade, o Rio Grande do Sul incrementou 52\% no mesmo período passando de 1.960 quilos por hectare para 2.970.

Gráfico 4 - Produtividade da soja no Rio Grande do Sul e Paraná entre 2006 e 2016

\section{Produtivdade $(\mathrm{Kg} / \mathrm{Ha})$}

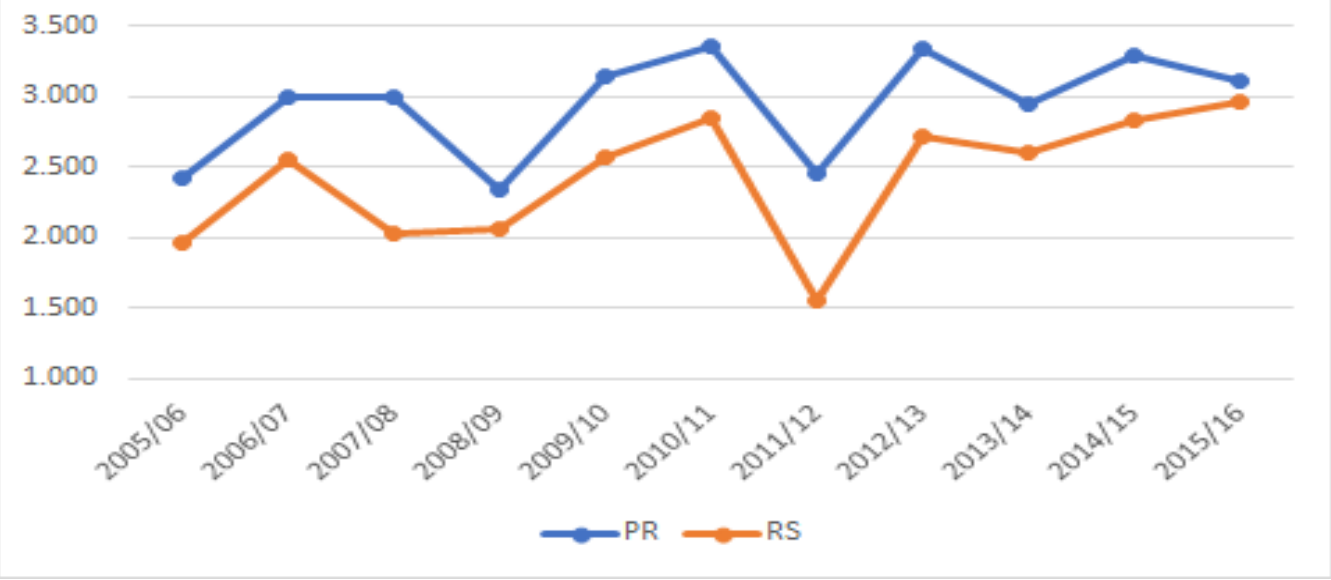

Fonte: CONAB (2018). 
Nisto, reitera-se o grão de soja, no que a exportação apresentou uma mudança dinâmica na distribuição da participação dos três estados do Sul conforme pode ser observado no quadro 2. Em uma observação inicial que se faz, destaca-se primeiramente Santa Catarina, quando se mostra, em 2006, o maior exportador do produto com $37 \%$ de participação, no que em valor isso se mostra em US\$828.095.066. No entanto, apesar de apresentar um aumento de suas exportações entre 2006 e 2016 no montante de 64\%, no final do período analisado o estado perdeu cerca 20\% de participação, alcançando US\$1.355.013.674.

Quadro 2 - Exportação da soja da região Sul (em dólares)

\begin{tabular}{|c|r|r|r|}
\hline Ano & Rio Grande do Sul & Santa Catarina & Paraná \\
\hline 2006 & $\mathrm{R} \$ 552.776 .413$ & $\mathrm{R} \$ 132.316 .955$ & $\mathrm{R} \$ 590.114 .026$ \\
\hline 2007 & $\mathrm{R} \$ 1.029 .845 .952$ & $\mathrm{R} \$ 375.646 .992$ & $\mathrm{R} \$ 1.103 .382 .967$ \\
\hline 2008 & $\mathrm{R} \$ 1.304 .880 .452$ & $\mathrm{R} \$ 384.452 .059$ & $\mathrm{R} \$ 1.917 .225 .872$ \\
\hline 2009 & $\mathrm{R} \$ 1.731 .106 .024$ & $\mathrm{R} \$ 106.811 .504$ & $\mathrm{R} \$ 2.266 .419 .860$ \\
\hline 2010 & $\mathrm{R} \$ 1.560 .749 .094$ & $\mathrm{R} \$ 318.817 .757$ & $\mathrm{R} \$ 2.498 .089 .213$ \\
\hline 2011 & $\mathrm{R} \$ 2.807 .924 .613$ & $\mathrm{R} \$ 580.029 .438$ & $\mathrm{R} \$ 3.484 .121 .615$ \\
\hline 2012 & $\mathrm{R} \$ 1.958 .038 .639$ & $\mathrm{R} \$ 614.018 .094$ & $\mathrm{R} \$ 3.565 .282 .598$ \\
\hline 2013 & $\mathrm{R} \$ 4.351 .085 .090$ & $\mathrm{R} \$ 730.032 .665$ & $\mathrm{R} \$ 4.655 .150 .833$ \\
\hline 2014 & $\mathrm{R} \$ 3.971 .249 .821$ & $\mathrm{R} \$ 1.037 .287 .984$ & $\mathrm{R} \$ 4.068 .547 .404$ \\
\hline 2015 & $\mathrm{R} \$ 3.627 .219 .578$ & $\mathrm{R} \$ 625.979 .633$ & $\mathrm{R} \$ 3.878 .411 .504$ \\
\hline 2016 & $\mathrm{R} \$ 3.155 .794 .056$ & $\mathrm{R} \$ 3.495 .924 .640$ \\
\hline
\end{tabular}

Fonte: Comex Stat, 2019.

Por outro lado, o Rio Grande do Sul apresentou a maior evolução no período uma vez que teve um incremento de $410 \%$ nas exportações do grão de soja, passando de $\$ 739.244 .042$ para \$3.773.669.712. Tal evolução garantiu que em 2016 quase metade dos grãos de soja exportados na região Sul fosse oriundo do Rio Grande do Sul.

\subsection{Emprego formal no cultivo de soja}

De modo a facilitar e possibilitar uma compreensão didática em relação ao emprego formal agrícola no Brasil, é importante refletir brevemente sobre o cenário que antecedeu o 
período estudado (2006 - 2016), para então adentrarmos na análise de dados sobre a situação do mercado de trabalho no período de expansão da exportação da soja no território brasileiro.

Conforme observou Teixeira (2005), o Brasil passou por uma modernização agrícola heterogênea, isto, pois, as regiões Sul e Sudeste foram as que mais de desenvolveram nas últimas décadas em relação aos demais estados brasileiros. A partir de 1970 a soja ganhou grande espaço no setor rural da região Sul e motivou a implantação de agroindústrias.

Bernardelli (2018), ao consultar as colocações de Silva, Monarin e Afonso (2017), coloca que a agricultura brasileira pós 1970 apresenta forte desenvolvimento, crescendo a taxas anuais em torno de $4 \%$ a $7 \%$, cumprindo com demandas urbano-industrial como gerar superávit nas exportações, cooperar com o crescimento do PIB e abastecer o mercado interno.

Logo, no que diz Bernardelli et al. (2018), o Estado teve grande participação no impulsionamento da modernização agrícola, haja vista que houve uma facilitação para o acesso ao crédito rural, além da influência em relação a fiscalização, comercialização, preços, entre outros. Contudo, a partir da década de 80 o Estado não tinha mais condições de continuar dando suporte anteriormente oferecido, inclusive em relação ao crédito rural, o que refletiu em benefícios para grandes proprietários de agriculturas em detrimento dos pequenos produtores. Para Tedesco (2001), "esses produtores em áreas menores que conseguiram sobreviver foram obrigados, muitas vezes, a se especializar em uma cultura ditada pelo mercado ou pela agroindústria, organizando-se, assim, em novas bases técnicas."

A década de 1990, como consta ainda Bernardelli et al. (2018), foi marcada por turbulências no setor econômico, contudo, este ainda destaca que a produtividade e modernização no campo continuaram decolando através da evolução de máquinas, agrotóxicos, fertilizantes, outros produtos. O autor complementa que, em sentido contrário, o mercado de trabalho rural sofreu com a modernização, motivando diversas migrações do trabalho no campo para a cidade além da substituição da força de trabalho humana por máquinas. Nisto, Kageyama (2004) contribui que entre 1960 e 1980, "todos os estados brasileiros, mesmo os que apresentaram intensificação da produção, registraram substanciais quedas no emprego agrícola, indicando baixa capacidade de geração de emprego neste setor."

Desde o início do desenvolvimento tecnológico, o crescimento no setor agrícola tem sido constante e dinâmico até os dias atuais. Com olhar para ao período estudado (2006-2016) verifica-se que a taxa de empregos formais no campo tem diminuído cada vez mais. Principalmente com a elevação da demanda de exportação de soja que exige uma produção acelerada. 
Para Bezerra e Elias (2011), existe uma histórica concentração da população economicamente ativa no setor primário, onde somente em 1963 editou-se o Estatuto do Trabalhador Rural, consolidando de fato as leis trabalhistas e a captura política e institucional das relações de trabalho no meio rural. Com isso, pode-se considerar que o Estado passou a ter papel fundamental no incentivo à mão-de-obra no campo, como já mencionado. Em 1989, Kageyama e Bergamasco (1989) já relatavam que nas duas últimas décadas (1970 - 1980) o Brasil passou por um processo de modernização e industrialização da agricultura, a partir disso podendo associar com um potencial de competitividade maior no mercado.

Trazendo para o recorte temporal da pesquisa, mesmo que entre os anos de 2006 e 2016 o setor agrícola tenha gerado cerca 27.357 novos empregos formais (RAIS, 2019), na cultura de soja esse índice não demonstrou a mesma tendência uma vez que a cultura de soja na região Sul apresentou uma variação de 1.882 para 1.496 empregos, isto é, um decrescimento de $21 \%$. Conforme pode ser observado no quadro 3, o estado de Santa Catarina foi o que teve a maior transformação com redução de 53\%. A maior variação absoluta ocorreu no Rio Grande do Sul com uma perda de 205 postos de trabalhos formais.

Quadro 3 - Variação dos empregos formais na produção de soja

\begin{tabular}{|c|c|c|c|}
\hline Ano & Paraná & Santa Catarina & Rio Grande do Sul \\
\hline 2006 & 1010 & 74 & 798 \\
\hline 2007 & 924 & 45 & 730 \\
\hline 2008 & 1067 & 100 & 651 \\
\hline 2009 & 1079 & 72 & 671 \\
\hline 2010 & 894 & 70 & 602 \\
\hline 2011 & 910 & 35 & 621 \\
\hline 2012 & 890 & 36 & 595 \\
\hline 2013 & 869 & 36 & 595 \\
\hline 2014 & 880 & 39 & 566 \\
\hline 2015 & 887 & 37 & 580 \\
\hline 2016 & 868 & 35 & 593 \\
\hline Variação (2006-2016) & $-14 \%$ & $-53 \%$ & $-26 \%$ \\
\hline
\end{tabular}

Fonte: RAIS (2019).

Obs: Dados extraídos com a "СBO ocupação 2002" de "Trabalhador na cultura de soja". 
O último estado que compõe a região Sul, Santa Catarina abarcou a variação mais preocupante em relação aos registros de trabalho formal na agricultura de soja dentro do período. Em 2006 o estado catarinense contava com 74 registros, em 2016 apenas 35. Foi o estado da região que teve maior nível de variação registrado, alcançando $-53 \%$ de registros de empregados formais na produção de soja.

No que tange a faixa etária dos trabalhadores, conforme o quadro 4 observa-se que a maior variação dos empregos formais na região Sul está concentrada nos jovens. O grupo de idade de 30 a 49 também apresentou uma queda, porém em menor proporção, variando entre $26 \%$ e $27 \%$. Esse cenário se altera apenas com os trabalhadores com idade acima de 50 anos do qual teve um aumento de $24 \%$ na quantidade de empregos.

Quadro 04: Distribuição por idade de empregados no cultivo da soja na região Sul

\begin{tabular}{|l|r|r|r|}
\hline Grupo Idade & 2006 & 2016 & \multicolumn{1}{c|}{ Variação } \\
\hline 15 a 17 & 14 & 4 & $-71 \%$ \\
\hline 18 a 24 & 212 & 127 & $-40 \%$ \\
\hline 25 a 29 & 233 & 152 & $-35 \%$ \\
\hline 30 a 39 & 563 & 414 & $-26 \%$ \\
\hline 40 a 49 & 528 & 388 & $-27 \%$ \\
\hline 50 a 64 & 315 & 390 & $24 \%$ \\
\hline 65 ou mais & 17 & 21 & $24 \%$ \\
\hline Variação Total & 1.882 & 1.496 & $-21 \%$ \\
\hline
\end{tabular}

Fonte: RAIS (2019).

A conjuntura apresentada demonstra que, assim como já foi constatado em países mais desenvolvidos, a juventude campesina, seja por falta de políticas públicas de incentivos a permanecer no campo ou por salutar uma condição financeira melhor, pouco tem se interessado em buscar uma carreira no campo, resultando em pequeno processo de êxodo rural jovem.

\section{Discussão e análise}

O desenvolvimento do Brasil em determinados períodos foi pautado pelas exportações de algumas culturas em específico, sendo o primeiro caso relacionado ainda ao período 
colonial, quando a cultura da cana de açúcar foi importante para o desenvolvimento, ainda assim, a renda gerada durante esse período ficou concentrada, não permitindo que a atividade exportadora gerassem efeitos multiplicadores sobre os demais setores da economia. Conforme Oliveira, Cardoso e Strassburg (2016), a cultura do café, já nas primeiras décadas do século XX, trouxe características desenvolvimentistas e oportunizaram o crescimento a partir das exportações, sendo a renda obtida direcionadas a construção de ferrovias e impulsionaram o surgimento de algumas indústrias em São Paulo.

O progresso no desenvolvimento das cidades advindo dos benefícios promovidos pelo agronegócio não tem se limitado a impactar apenas os maiores centros produtores já consolidados, mas também tem corroborado para o desenvolvimento de municípios no interior dos estados. Tais benefícios são evidenciados abaixo:

\begin{abstract}
"O movimento de expansão e interiorização da soja estimulou o desenvolvimento de infraestrutura e qualidade de vida no interior do país. Além de forçar o desenvolvimento de rodovias, hidrovias, portos, serviços de comunicação e fornecimento de energia elétrica houve a criação e o desenvolvimento das cadeias pré e pós-porteira e outras cadeias que se beneficiaram diretamente da soja como a avicultura, bovinocultura, etc. Esse desenvolvimento provocou mudanças sociais importantes como a fixação da população em novas regiões, diminuindo a pressão sobre os grandes centros metropolitanos. Nestes centros agrícolas dentre os quais podemos citar Passo Fundo (RS), Santa Rosa (RS), Londrina (PR), Cascavel (PR) [...]" (ABAG, 2015, p. 7).
\end{abstract}

Neste sentido, assim como o açúcar e o café tiveram papel no desenvolvimento do país, o movimento de expansão e interiorização levando o desenvolvimento, a infraestrutura e a qualidade de vida estão intimamente relacionadas com a produção de soja. Destaca-se, neste sentido, um IDH médio $10 \%$ superior nas cidades que produziam soja àquelas que não produziam soja, também um crescimento médio superior às outras cidades. (ABAG, 2015)

No que se refere à geração de renda e emprego, "a agropecuária é forte geradora de empregos, sobretudo se consideramos os impactos diretos, indiretos e o efeito renda, que ocorre devido ao consumo produzido com a riqueza gerada (ABAG, 2015, p. 7). Estudos estimam que a produção de soja tenda a gerar cerca de 0,2 empregos por hectare conforme Sachs (2004), Roessing e Lazzarotto (2004) e Gazzoni (2012). Sachs (2004) destaca ainda não ser possível considerar a produção mecanizada de grãos (soja) como representativa do conjunto de agronegócios, uma vez que cria um número diminuto de empregos diretos. Neste diapasão, destaca-se, de início, que não necessariamente o alto volume na produção da soja, já destacado, relaciona-se diretamente a geração de empregos, haja visto que a relação emprego $\mathrm{x}$ hectare é baixa e a mão de obra necessária neste tipo de cultivo pequena. 
Sachs (2004) expõe que a produção de hortigranjeiros requer pelo menos cem vezes mais trabalhadores por hectare do que a de grãos altamente mecanizados, desta forma incide sobre a produção da soja não só o baixo número de empregos gerados por hectare, mas também a alta mecanização e tecnologia desenvolvida neste tipo de cultura que precisa de cada vez bem menos trabalhadores para cobrir áreas cada vez maiores.

Há muito a agricultura deixou de carregar consigo características de subsistência e/ou de consumo interno e desde a década de 80 tem uma expansão da produção econômicaindustrial baseada basicamente em uma dinâmica de produção industrial. Mattei (2015) destaca a substituição das lavouras tradicionais por culturas agrícolas modernas e com baixo uso e mão de obra, também com a incorporação de inovações tecnológicas em todas as etapas do processo produtivo, sobretudo onde eram necessárias quantidades maiores de mão de obra - cana de açúcar, algodão, café, entre outros - por culturas que exigem menos cuidados específicos, pautada por influências externas (exportações) e não necessidades internas.

No que diz respeito às relações de trabalho no ramo agrícola, especificamente na produção de soja, percebeu-se uma exponencial queda na taxa de empregos formais entre os anos de 2006 e 2016, as quais podem ser diretamente associadas a um rápido movimento de modernização que impossibilitou a adequação da comunidade rural através de uma possível alteração de perfil do profissional do contratado. Deve ser ainda ponderado o trabalho volante (boia-fria, diarista), como também a terceirização do trabalho - aspecto já recorrente no campo.

Norteando-se nas palavras de Bernardelli et. al. (2018), entende-se que "a modernização agrícola possui efeito perverso ao nível de empregabilidade, pois substitui mão de obra por equipamentos". Dessa forma, não houve apenas uma redução da empregabilidade, como também uma exigência rígida de força de trabalho mais qualificada para o setor, fator que contribuiu para ingressos informais no ramo agrícola.

\section{Considerações finais}

O trabalho objetivou analisar a empregabilidade formal do cultivo de soja na região Sul do Brasil no período de 2006 a 2016, de modo a comparar o progresso da exportação de soja nos últimos anos em relação aos resultados obtidos.

A Teoria da Base da Exportação parte da premissa que o desenvolvimento de uma região ocorreria por meio do incremento do nível de exportações. Como consequência, o efeito 
multiplicador promoveria o desenvolvimento de outras atividades e setores, assim como a criação de novos postos de trabalhos.

No entanto, neste estudo não foi possível comprovar a premissa de geração de novos empregos no cultivo da soja considerando o recorte regional e temporal adotado na pesquisa. Entre os anos de 2006 e 2016, cerca de 386 postos de trabalhos formais foram extintos, queda de $21 \%$, enquanto as exportações aumentaram de forma progressiva, tornando a soja o líder de exportações (representando em média mais de $20 \%$ de todas as exportações do Brasil), com uma projeção de se tornar até 2020 o maior exportador de soja do mundo, deixando para trás os Estados Unidos. O estado com maior queda foi o Rio Grande do Sul com 205 postos extintos (variação de 26\%).

Visto o processo do que chamamos de êxodo rural jovem, além do que já foi considerado em relação a falta de incentivos e políticas públicas, também aqui levanta-se a interpretação a partir do que foi revisado nos trabalhos de Kageyama e Bergamasco (1989), Mattei (2015) e Bernardelli (2018), no que os autores constatam um processo de modernização da agricultura. Esse processo, ao mesmo tempo em que trouxe potencial competitivo ao mercado, substituiu grande parte da força de trabalho humana, para tanto, é necessário futuros trabalhos e análises que apontem os pontos positivos e negativos deste processo mais detalhadamente, pois em primeira interpretação, a modernização afetou a geração de emprego.

As consequências vistas através da ausência de empregos formais traduzem não somente o desemprego causado pela ligeira modernização rural como também reflete a questão da informalidade como resultado. Como visto no presente estudo, a rápida industrialização do campo passou a exigir força de trabalho mais qualificada, e diante de sua inexistência à época, muitos empregados rurais optam pela informalidade como solução do problema.

Para finalizar, reitera-se aqui o fato de que são necessários futuros trabalhos que analisem mais detalhadamente a relação entre a exportação e o emprego formal da soja, mensurando o impacto de uma variável sobre a outra.

\section{Referências}

ABAG, Associação Brasileira de Agronegócio. 0 futuro da soja nacional. Impactos socioeconômicos da Ferrugem Asiática na cadeia da soja nos próximos dez anos, 2015. 
Disponível em: <http://www.abag.com.br/media/images/0-futuro-da-soja-nacional---ieag--abag.pdf>. Acesso em: 06/07/19.

AEC. Atlas Da Complexidade Econômica. Acessado em: 23/05/2019. Disponível em: http://atlas.cid.harvard.edu.

BELLATO, M. A.; FONTANA, Denise Cybis. El niño e a agricultura da região Sul do Brasil. Passo Fundo: Embrapa, 2011.

BERNARDELLI, Luan Vinicius et al. A Formalização do Trabalho na Agricultura: uma análise das microrregiões do Estado do Paraná. Revista Paranaense de Desenvolvimento-RPD, v. 39, n. 135, p. 47-67, 2018.

BEZERRA, Juscelino Eudâmidas; ELIAS, Denise. Difusão do trabalho agrícola formal no Brasil e sua dinâmica multiescalar. Investigaciones geográficas, n. 76, p. 104-117, 2011.

EMBRAPA, Empresa Brasileira de Pesquisa Agropecuária. Soja em números.

Disponível:<https://www.embrapa.br/soja/cultivos/soja1/dados-economicos>. Acesso em 06/07/2019.

JÚNIOR, Valdemar João Wesz. O mercado da soja no Brasil e na Argentina: semelhanças, diferenças e interconexões. Século XXI: Revista de Ciências Sociais, v. 4, n. 1, p. 114-161, 2014.

KAGEYAMA, Angela; BERGAMASCO, Sonia MP. A estrutura da produção no campo em 1980.

Perspectivas: Revista de Ciências Sociais, 1989.

LIMA, E. C; LIMA, E. P. C; EVAS, I. M; TEIXEIRA, M. S. G. Teoria da base da exportação e a sua relação com o desempenho econômico: o caso do estado de Santa Catarina. Textos de Economia, Florianópolis, v.16, n.1, p.95-116, jan./jun.2013.

MATTEI, LAURO. Emprego agrícola: cenários e tendências. Estud. av., São Paulo, v. 29, n. 85, p. 35-52, Dez. 2015. Disponivel em:

$<$ http://www.scielo.br/scielo.php?script=sci_arttext\&pid=S0103-

$40142015000300004 \&$ Ing=en\&nrm=iso>. Acesso em 13 de agosto de 2019.

NORTH, D. C. Teoria da localização e crescimento econômico regional. In SCWARTZMAN, J.

Economia Regional. Textos escolhidos. Belo Horizonte: Cedeplar, 1977.

OLIVEIRA, G. B. O desenvolvimento das regiões: uma iniciação às estratégias de desenvolvimento regional e urbano. Curitiba: Protexto, 2008.

OLIVEIRA, Nilton Marques de; CARDOSO, Bárbara Françoise; STRASSBURG, Udo. Algumas considerações sobre a Base De Exportação das regiões brasileiras. Revista Interdisciplinar Científica Aplicada, Blumenau, v.10, n.1, p.66-80, TRI I 2016.

OLIVEIRA, Nilton Marques de; NÓBREGA, Adalmário Mendes; MEDEIROS, Messias Rodrigues. Desenvolvimento Econômico e Regional segundo a teoria da base de exportação. Revista Tocantinense de Geografia, v. 1, n. 01, 2012.

PIFFER, Moacir et al. A base de exportação e a reestruturação das atividades produtivas no Paraná. CUNHA, MS; SHIKIDA, PFA; ROCHA Jr. WF Agronegócio paranaense: Potencialidades e desafios. Cascavel: Edunioeste, p. 56-72, 2002.

REUTERS. Brasil pode superar EUA na produção de soja em 2019/20. Editora Abril: Exame, 2019. Disponível em: <https://exame.abril.com.br/economia/brasil-pode-superar-eua-naproducao-de-soja-em-2019-20/>. Acesso em 06/07/19.

RICHARDSON, H. W. Economia regional: teoria da localização, estrutura urbana e crescimento regional. Rio de Janeiro: Zahar, 1975. 
SACHS, Ignacy. Inclusão social pelo trabalho decente: oportunidades, obstáculos, políticas públicas. Estud. av., São Paulo, v. 18, n. 51, p. 23-49, Aug. 2004.

SCHLESINGER, Sergio. Soja: o grão que segue crescendo. Grupo de Trabalho sobre

Desenvolvimento e Meio Ambiente nas Américas, Documento de Discussão, v. 21, 2008.

SILVA, AC da; LIMA, EPC de; BATISTA, Henrique Rogê. A importância da soja para o agronegócio brasileiro: uma análise sob o enfoque da produção, emprego e exportação. V Encontro de Economia Catarinense, 2011.

SIMÕES, Rodrigo Ferreira; LIMA, Ana Carolina da Cruz. Teorias do desenvolvimento regional e suas implicações de política econômica no pós-guerra: o caso do Brasil. Belo Horizonte:

Cedeplar, 2009.

SOUZA, N. J. Conceito e aplicação da teoria da base econômica. Perspectiva econômica, UNISINOS. São Leopoldo, RS. v. 10, n. 25, de p. 117-130, março 1980.

TEIXEIRA, J. C. Modernização da agricultura no Brasil: impactos econômicos, sociais ambientais. Revista Eletrônica da Associação dos Geógrafos Brasileiros, Três Lagoas-MS, v.1, n.2, p.21-42, 2005.

WREGE, Marcos Silveira et al. Atlas climático da região sul do Brasil: estados do Paraná, Santa Catarina e Rio Grande do Sul. Pelotas: Embrapa Clima Temperado; Colombo: Embrapa Florestas, 2012. 